\title{
Hauntings of Bodies, Selves, and Houses:
}

A Comparative Reading of

Three of Emily Carroll's Short Horror Comic Stories

\section{Eliza O'Donnell, Loyola University}

This essay examines how the themes

of domesticity, gender, and the function of

bodies within the horrific realms of haunted

domiciles function in three of comic and

graphic novel author Emily Carroll's short

graphic horror stories. The essay discusses

the short digital horror comic "All Along

the Wall" (2014), as well as the short horror

comics "A Lady's Hands are Cold" and "The

Nesting Place," both published in Carroll's

2014 collection Through the Woods. Each

of these stories presents the reader with a

ghost and/or haunting that has an uncon-

ventional relationship to corporeality, as well

as with a female protagonist who is preyed

upon in a domestic setting.
Definitions of ghosts vary widely across cultures, epochs, and scholastic theorizations, but the basis of these definitions and the pursuits of categorization they entail identify that ghosts are entities without bodies, and moreover, that ghosts often covet a corporeal form in some way. The severing of the connection between the spirit and the flesh begets ghosts-but what comes about when that connection is not quietly severed by death, but is instead shaped and consumed by desire and monstrosity? Comic artist and graphic novelist Emily Carroll explores the ghastly possibilities of corporeal existence for ghosts in many of her comics, in both digital and print media. Her 2014 digital horror comic "All Along the Wall" presents a metanarrative of an adolescent girl telling a child a scary story with an unsatisfying (but implicitly sinister) ending while they both hide away from a Christmas party in the adolescent's English country home. The story and characters in this short story comic 
precede those of the final comic in Carroll's original short horror comic collection Through the Woods (2014), titled "The Nesting Place." "The Nesting Place" follows a teenage girl who, shortly after her mother's death, visits her older brother in his fiancée's country home and quickly becomes embroiled in a game of cat and mouse with an eldritch body-snatching parasite. The themes of preyed-upon bodies and the ghosts of the past selves they produce also direct the plot of another story in Through the Woods, "A Lady's Hands are Cold." Carroll's aptitude for troping fairy tale motifs shines in this story of a young aristocratic woman whose male-dictated marriage to a rich widower leads to a deadly discovery when she acts upon the pleas of the mournful song that she hears from the walls of her new home each night. Here I argue that each of these works presents the reader with a haunting by a ghost defined not by a broken connection to body and place, but by a corrupting usurpation of that connection by predatory forces that share a home with the ghost in bodily and architectural domiciles. Carroll's use of domesticity guides this predatory, corrupted ghostliness, and also makes space in her stories' houses for a transformative characteristic of ephemerality present in not only the ghostly subject of each of the three stories' hauntings, but also the object(s) of the hauntings-which, of course, share domestic space with that which haunts them.

Understanding the nature and function of the type of ghosts that define the hauntings in these three stories prompts an exploration of the presence of more traditionally defined ghosts, as well as how each of them expresses and incorporates the quality of ephemerality. Ghosts that are spirits dispossessed of bodies come up explicitly only in "All Along the Wall," wherein a child frames the metanarrative by asking for a ghost story and noting the distinct absence of ghosts in the story told to her. While the other two stories do not outright mention or depict ghosts of this type, both contain qualities of haunting and spiritual presences. "The Nesting Place" brings in a variety of supernatural and/or paranormal creatures, the most relevant of which certainly possess haunting qualities and distinctly bring up the question of how spirits or souls figure into their existence. The feature creature of "A Lady's Hands are Cold" seems at first to be a ghostly presence, and although the twist reveal of the story complicates that, the creature and the girl it desires both retain a certain ghostly ephemerality. While identifying the presence of more conventional ghosts in these stories is a complex endeavor, each story plays upon aspects and ideas central to ghosts and ghostliness in order to present its own ideas on hauntings and monstrosity.

With "All Along the Wall," Carroll constructs a textual entry point for these three stories of domestically twisted hauntings, succinctly tying her ghostly monster to the characters' domestic interior. The three-page digital comic follows Lottie, a child of about ten, as she sneaks upstairs 
from a Christmas party hosted in a lavish countryside house. She steps curiously into a darkened bedroom, and its owner-Rebecca, the young teenage daughter of the party's hostess-soon discovers her. Lottie promptly requests a ghost story, a Christmas Eve tradition, and Rebecca gladly tells her a "just like you/[...] just like this one" story of a girl in a house frightened at night by a crawling, scuttling creature that creeps along her bedroom walls, ending with the reveal that the creature took over the girl's body from right under her mother's nose (1-2). The story dissatisfies Lottie, who says it was not truly scary and asks, "Where was the ghost?" to which Rebecca calmly replies, "There was no ghost" (3). Both girls are correct in the absence of the traditional type of ghost Lottie visualizes, but as Lottie tells Rebecca that she knows she went missing last summer, getting lost in a cave in the nearby woods for three days_-"YOUR mother told [my mother] ALL about it"-Carroll makes only the reader aware that the enfleshed, ephemeral being from Rebecca's story took over her body (3). Rebecca is the girl who has been preyed upon in her own bedroom, under her mother's not-watchful-enough eye, but what made Rebecca's body its home is not even human. Moreover, the way Carroll depicts this creature unfurling and arching over Lottie's cross-legged form in a stretching web of red threads indicates its predatory intentions, showing that it now wants to extend that home into another girl's body (3). The presentation of the scary story narrative and its metanarrative twin, the twist reveal of what truly happened to Rebecca, both integrate an element of domestic horror, tinged with simultaneous ephemerality and ghastly realness, into the story.

As with all three of these stories, this first of two narratives to feature the creature to which Carroll gives no name but which can accurately be called the "red-thread creature" contains numerous layers of domestic, feminized, bodily, and ghostly horror. Each of these elements operates with a strength of its own in "All Along the Wall," but they are all contained within, and therefore tie in with and play into, the horror of the domestic sphere. The narrative and illustrations do not demarcate a specific time setting for this story, but, judging from the domestic trappings and the characters' dress, it is within a decade or two of the turn of the twentieth century that Lottie has this near-fateful visit during a Christmas celebration. Writing on the use of the emblematic haunted house in media, Elizabeth Wilson finds that "fear has a location and, in a newly urban society, fear migrated to the built environment" (113). Though this story exists far from a city environment, the active horror that takes place within it is contained neatly within the bedroom walls of a stately country manor-a place of safety for the preyed-upon human inhabitants and domestic guests, as well as the creature trying to establish its existence in its own carved-out space.

In line with the expectations and potential subversions of her genre, Carroll chooses well 
in selecting a young adolescent girl as the avatar that the red-thread creature uses to create its own domicile within its prey's domicile. In Jeffrey Andrew Weinstock's extensive analysis of how and why women tell and continue telling ghost stories, he notes that $19^{\text {th }}$-century Gothic women's ghost stories attribute a transgressive function to "what gets 'ghosted'-what tries to present itself but can only achieve a half-life existence" (138). In constructing the human-housed monster that drives the plot of "All Along the Wall," Carroll doubly ghosts Rebecca and the red-thread creature that made a home of her body. It is pertinent to note, though, that this ghosting does not denote loss of material power, at least for the red-thread creature. Weinstock extends his notion of "ghosting" with Terry Castle's queered analysis of the storytelling strategy, which, when lesbian and queer writers use it, becomes "the very trope that evaporates [... that] can also solidify" (Castle qtd. in Weinstock 139). Though Carroll has not publicly disclosed her exact sexuality', her marriage with a woman proves that she is certainly queer.

Carroll's perspective as a queer woman is accordingly present throughout her work, particularly here, wherein she employs the twin ghosting of Rebecca and the red-thread creature as a force that simultaneously manifests ephemerality and materiality. While Rebecca's body is intact, able to be rapidly de- and reconstructed at the red-thread creature's whim, Rebecca's spirit is no longer intact, if it remains at all. Her positioning as a teenage girl is also pertinent here: particularly in her early-twentieth-century hetero-patriarchal family home, Rebecca's body and existence are caught between girlhood and womanhood, rendering her a uniquely existentially uncertain status as a household member, and as a horror character archetype. The vitality and shifting existence of young women have long been vilified and feared, and Carroll is drawing that out in Rebecca as a perversion of in-between states in young women. As for the red-thread creature, its existence falls right on the mark of Weinstock's notion of "half-life existence": for whatever bodily vitality it may possess, the creature cannot fully exist socially or, arguably, even domestically. Revealing itself would mean loss of its domesticated human flesh and human house, not to mention that these constructed domiciles have necessitated its move away from its original home in the cave where Rebecca's body was lost for three days and where her spirit was likely lost for good. Carroll even textually constructs a half-life for the creature's origins: the panel in which the creature enters and teems within Rebecca's limp body, her face hollowed, eyeless and blue, from a pool of underground standing water is only visible when the reader mouses over the panel in which Lottie asks if Rebecca was mute for a week after returning home from the woods "because you saw something very frightening?" (3). These varied and interconnected layers of half-alive ephemerality ultimately function as a critique of how hetero-patriarchal domestic spheres twist $1 \quad$ At least, not in any sources that can be readily found on the Internet in a diligent search. 
and use female bodies.

Carroll extends and multiplies the horrors of the red-thread creature and its carving out of feminine domiciles in her longer-form short comic story, "The Nesting Place." In "The Nesting Place," Carroll reopens the door to the country house that the red-thread creature occupies the human inhabitant of-but now, Rebecca's rehomed body is the head of the household, with a fiancé who brings his sullen teenage sister home to the rural estate on her summer holiday from boarding school. The story is the longest one in Through the Woods, and Carroll's narrative once again follows a young, dark-haired girl who contemptuously wanders off from most social conventions. This time, the new player in the domicile is an adolescent, Bell, whose storyline is not marked by curiosity and ignorance but by grief, resentment, and the ultimate horrifying discovery of what she actually shares domestic space with. As she is leaving her boarding school to meet her brother, Clarence, Bell recalls the stories of monsters that her recently deceased mother always asserted the existence of, particularly "the BURROWING KIND. The sort that crawled into you and made a home there. [...] The monster that ate you alive from the inside out" (Loc. 70, Panel 2). Not long into her stay at Rebecca's house, Bell has her disbelief in these stories turned on its head. About a week of increasingly strange and unsettling occurrences around the house passes-Rebecca's teeth clicking and wiggling in her mouth while she eats dinner; the housekeeper, Madame Beauchamp, ominously warning Bell against venturing into the woods as Rebecca did several years before; Mme. Beauchamp disappearing after behaving strangely that evening and late that night; and all the while, Clarence acting cheerful and flippant as ever, with Rebecca mirroring his attitude and trying to engage Bell in gender normative activities that she is patently uninterested in, such as makeup and shopping. The day after Mme. Beauchamp supposedly voluntarily leaves the house, Bell spends an idyllic day in the woods before falling into the cave just as Rebecca had, and discovering that it was not Rebecca that had come out of the cave, but the red-thread creature wearing her skin. Bell wakes up in the house, having been rescued from the cave, and the red-thread creature reveals its methods and intentions to her: it has babies in the pool in the cave, and Bell's skin will be perfect for them. Bell manages to convince the creature that its plan of taking her skin and going to London with its babies and Clarence will ultimately thwart the creature's reproductive aims because of London's hostile, polluted environment, after which Clarence arrives to take Bell to the doctor, which makes "Rebecca" happy. As the siblings drive into the open countryside, Bell hands Clarence an apple-and his teeth click and wiggle against it. Bell's eyes open wide in horror as she realizes she is in a car, alone, with more of the red threads wearing her brother's skin. Carroll closes the story there. 
This longer-form narrative of the domestic horrors of girlhood and ghosts housed in corrupted flesh and convention extends many of the themes of "All Along the Wall," while also drawing upon new ones borne from the connections and growth of those themes. Carroll's work with the conventions of her genre once again comes out here in modes that critique gender, social, and familial norms as they manifest in the domicile. Queer literature scholar Ardel Haefele-Thomas comments on the phenomenon of the Gothic genre as "a proverbial safe space" for women writers, and especially queer women writers, who find that "writing within a liminal genre like Gothic has enabled them to more honestly and thoroughly critique restrictive social and cultural conventions such as," in the case of Carroll's writing of Bell, how young women ought to handle themselves and their emotions socially, as well as how non-normative female bodies signify socially (169). Bell's health status as a depressed, stocky teenage girl who wears a leg brace and often uses a cane sets her apart from her peers and family at best; at worst, the red-thread creature pathologizes her body's build and capability. The creature rebuts Bell's protests that someone at school or in her family would notice if the creature expelled her spirit from her body by pointing out that Clarence would "be so thrilled you're no longer sullen and depressed he'll never question the change!" and also targets Bell's body with an assertion that her peers "will much prefer you once my babies stretch you into something tall, slim, and pretty" as the red threads have with Rebecca's figure, which is unnaturally lithe and rosy throughout the story (Loc. 94, Panels 1, 2). While horrifying in a uniquely gendered way, Carroll plays this dynamic as a subversion of the usual handling of disability in not only horror but also in comics.

Aidan Diamond and Lauren Poharec write on how comics present and perpetuate othered bodies and othering of various kinds, specifically exploring stereotypes of characters and bodies with disabilities and/or medicalized conditions. Carroll's characterization of Bell and of her enemy as explicitly trying to form her into a normalized social body directly subverts the trope in the comic genre of making "stereotypical representations [of disabled people that] respond to and reinforce an ideology of ability: the essentialist assumption that able-bodiedness must be preferred in all circumstances," even the circumstance of a predatory parasitic creature supplanting a spirit from a body, which Bell's peers and social circles would gladly, if unknowingly, accept (406). Setting this interaction between Bell and the red-thread creature, and their conversation's underlying implications, in a simultaneously domestic and alienating physical space-a guest bedroom of an estate house whose mistress has been made herself a home for a predatory, ghostly and ghosting being - keeps this horror of hetero-patriarchal standards firmly housed within the horror of the domestic. 
Adding to the horror and corrupting, haunting force of the red-thread creature is its status as mother. Female characters and figures drive the plots of both "The Nesting Place" and "All Along the Wall," whose protagonists have relationships with their respective mothers that, while complex, are not particularly unexpected for children of their ages carrying out a relationship with a mother who shares and perpetuates hetero-patriarchal domestic space and norms with her daughter. Mothers and motherhood make for arguably Freudian horror material, as Gina Wisker discusses in her analytical review of horror stories and tropes with a focus on domestic horror. "Mothers in horror are often engulfing and entrapping" to their children, especially their female ones, and "monstrous and surrogate mothers [who] desire to kill off children to preserve themselves and their own offspring" are a particular kind of threat that Carroll, with her penchant for folklore and fairytale, creates in her red-thread Rebecca (5). Carroll tropes domestic horror to have the red threads puppet Rebecca's skin to be kind and nurturing to the red-thread babies, and extend her maternal engulfing entrapment to Bell, whose personage and personhood it hopes to supplant for its babies' sake. The ghostly creature's folkloric attributes extend further in that the red-thread creature's motherhood comes to narratively function as both its seeming downfall and its greatest strength: Bell seems to wrest power for herself in pointing out red-thread Rebecca's vulnerability as a mother. "You claim to be such a GOOD MOTHER," Bell accuses the creature with regard to her babies' probable fate in London, "but what kind of heartless BEAST would chance their lives like this?" (Loc. 97, Panel 3). Whatever red-thread Rebecca's true feelings are, Bell's argument seems to have cowed her into submission, and Bell is free and safe- until the reveal that red-thread Rebecca's maternal workings have long since hollowed her brother's skin to make room for a paternal, monstrous counterpart. Red-thread Rebecca's motherhood has proven to be truly horrifying, operating in these manners and corrupting living beings into half-existent ghosts within its appropriated domiciles.

Carroll continues to trope folklore archetypes with similar effectiveness and to the ends of critiquing hetero-patriarchal norms in a domestic horror setting in her fairytale-style narrative, "A Lady's Hands are Cold." "A Lady's Hands are Cold" is not connected to "All Along the Wall" and "The Nesting Place" by recurring characters or settings, but it undoubtedly exists on the same thematic axis as these two stories: namely, if there is an archetypal "haunted house" story in Through the Woods, it is this one. Folklore scholar Christina Dokou describes Through the Woods as a collection that epitomizes the "fruitful threesome" of the Gothic, the fairy tale, and comic books. Dokou further characterizes "Carroll's gothic play with tradition [... as] a palimpsestic reading that shows traces of the text that her own piece of literature has devoured to sustain itself," an analysis 
that serves as both an apt description of this story and an uncanny precursor to how ghosts and haunting function within it $(572,576)$.

The horror of "A Lady's Hands are Cold" is put front and center from the outset, with the first page featuring the eerily short and apt lyrical description of the heteronormative patriarchal workings that shape the frame of this story and its characters. "There was a girl," Carroll begins this lurid tale, " $\&$ there was a man/and there was the girl's father/who said, 'you will marry this man," utilizing the narration to frame illustrations of said girl and man in profile, casting their relationship, individual selves, and wedding with airs of half-alive material ephemerality, as well as menace and suffering (Loc. 21, Panels 1-3). The narration follows the newly wed girl as she travels through the woods from her father's house to her new husband's manor. In this new domicile, she leads an existence evidently so bereft of her husband's presence that he becomes something of a menacing ghostly presence himself, particularly during the lavish dinners they are seated at together each night, where his predatory air intensifies. Rather than her husband having her share a marriage bed with him, the girl sleeps alone in her own bedroom, where each night she begins to hear a song seeping mournfully out from the very walls of the house, sung as follows:

I married my love in the springtime,

but by summer he'd locked me away.

He'd murdered me dead by the autumn, \& by winter I was naught but decay.

It's cold where I am and so lonely, but in loneliness will I remain,

unloved, unavenged, \& forgotten, until I am whole once again. (Loc. 25, Panels 1-5). After many nights of this, the girl's husband leaves for a hunting trip. Now the sole living being in the manor who holds domestic power, the girl dismisses the maids and uses a hatchet to cut open the wall, where she finds a shriveled pair of hands. The girl moves throughout the house, chopping and digging until she finds the entirety of her husband's murdered first wife, dismembered and scattered throughout, her ghostly white head singing its song once more to the girl when she discovers it. The girl gathers up the desiccated corpse pieces, brings them to her murderous husband's bedroom, and reassembles her predecessor's body on the floor, tying the enfleshed wraith together with bits of red ribbon. The corpse reanimates-and vows to rip the girl to pieces for having usurped her role as lady of the manor. The girl flees the bedroom, then the manor altogether as her husband returns from his hunt, and continues running until she finds herself deep into the woods.

Of the three stories discussed in this essay, "A Lady's Hands are Cold" is the one whose function and actors of the domestic horror are the most emblematic of the notion of the ghost- 
liness of these stories as predatory corruption of the body-spirit connection. In examining queer Gothicism, Haefele-Thomas observes, "as a genre, Gothic thrives on complications and constantly throws what we think we know and believe into confusion, often with subversive and disturbing results," and Carroll creates some truly viscerally disturbing results in her formulation of the being that haunts this story's protagonist and massive manor home (170). With regards to the husband's first wife, the original mistress of the manor, the narrative sets up key expectations for the reader and for the protagonist within the framing of the story and the house it takes place in, only to devastatingly complicate and subvert them. The dead wife's song emanates from varying places throughout the manor as "a low keening that SEEPED [...] FROM the HOUSE'S VERY BONES," very much in the manner of a ghost of the type that is simply spirit bereft of body (Loc. 25, Panels 5, 13). This typical ghostliness extends into the song's almost possessive influence on the living wife, even as her maids, more fixtures of the house than people, tell her not to worry about the ballad that has "settled into HER bones [...] until the girl's insides [became] clotted with HEARTACHE" as, night after night, she is forced to lay and listen to a song that seems almost to exist only to her (Loc. 28, Panel 1). With this seemingly traditional haunting as disturbing as it already is, Carroll then hacks into and takes apart the protagonist's and the reader's presumptions of what haunting being occupies this house with the reveal of the desiccated body parts spread throughout the house. The girl finds her predecessor's hands, arms, legs, feet, torso, and head in all of the places from which she heard the song originate, thus attributing the dead wife's body, not her spirit, with the ethereal power to have sung this song (Loc. 30-32). This wrathful, decaying wraith is all but impossible to definitively classify as a being who haunts within the bounds of horror tradition: she could possibly be called a ghoul, but to do so would deny her the totality of her spiritual power. This elision of classification is clearly in line with what queer women do with horror, per the writings of the scholars discussed throughout this essay, as well as exemplifying the true nature and horror of this story as one of a house haunted by the subduing and murder of women in domestic space and convention.

The themes present in "A Lady's Hands" continue to spin off of and multiply upon themselves as discourse goes on, but the most pertinent aspect of this story's domestic, ghostly horror is its sharp critique of how women's bodies and agency function within the domiciles that house the hetero-patriarchal system of marriage. This manor house is not haunted only by the wraith wife's song of her demise; her husband's ruthlessly hungry predation upon each wife, as well as the selves, lives and bodies each wife has lost, also haunt the enormous white manor and its surrounding lurid red gardens. The forces that operate within and through the physicality of the 
manor work well in the terms of Wilson's citation of Vidler's notion of seeing Romantically sublime buildings "as objectifying the various states of the body, physical and mental," which Wilson ties to her observation that "it is invariably women who activate the fear and the malice of the dwelling or who project it onto the house" (118). Both the wraith wife and the girl wife are activators and objects of this house and its malice, which is really the husband's hungering malice that has destroyed both his wives. Herein also lies Carroll's final subversion: in her fairy tale, a genre wherein the woods are where women are eaten, the girl wife must flee to the woods to escape being rent and consumed by either one of the manor's occupants: a lavish mansion has become and has always been more terrifying and threatening than any wild place.

Carroll makes all sorts of disturbing twists in these three stories to draw out the horror of being female in domestic spaces; her complex formulations of hauntings and troping of ghost and haunted house folklore serve only to produce more ghosts. The corrupted, ghostly predators of each story ultimately narratively consume the objects of their respective hauntings. Each one ends up transformed and ephemeral on the same level as that which plagues her, confined in domesticity: Lottie is left alone and confused in a dark bedroom that is not hers; Bell is trapped in a small space with something hungry that wears her brother's skin; and the girl is utterly wrecked, her eyes nothing but hollow blackness, looking as dead as the wraith wife that chased her from the house. The comic homes of Carroll's richly woven stories are replete with the terror of occupying a domestic space, especially as a non-normative girl or woman. Naturally, they all must occupy such a space, because per the title of Through the Woods, it is unwise to linger in a space outside of a domicile_-not that residing within one bodes well either. 


\section{Works Cited}

Carroll, Emily. "All Along the Wall." Digital comic. emcarroll.com, 2014.

"A Lady's Hands are Cold." Through the Woods, Margaret K. McElderry Books. Loc. 20-38 in Kindle

Digital Edition. 2014, New York.

"The Nesting Place." Through the Woods, Margaret K. McElderry Books, Loc. 68-99 in Kindle

Digital Edition. 2014, New York.

Diamond, Aidan, and Lauren Poharec. "Introduction: freaked and othered bodies in comics." Journal of Graphic Novels and Comics, vol. 8, no. 5, 2017, pp. 402-16.

Dokou, Christina. "Un(th)inkable tales: unimaginable folklore horror in Emily Carroll's Through the Woods." Journal of Graphic Novels and Comics, vol. 8, no. 6, 2017, pp. 527-87.

Haefele-Thomas, Ardel. "Queering the Female Gothic." Women and the Gothic, edited by Avril Horner and Sue Zlosnik. Edinburgh University Press, 2017, pp. 169-83.

Weinstock, Jeffrey Andrew. "Ghosts of Desire: Rose Terry Cooke, Alice Brown, Elizabeth Stuart

Phelps, and Helen Hull." Scare Tactics: Supernatural Fiction by American Women. Fordham University Press, 2008, pp. 136-71.

Wilson, Elizabeth. "Haunted Houses." AA Files, No. 67, 2013, pp. 113-118.

Wisker, Gina. "'Honey, I'm home!' Splintering the Fabrication in Domestic Horror." Femspec, vol. 4, no. 1, 2002, p. 108. 